\title{
Review
}

\section{Neuroprotection of the Perinatal Brain by Early Information of Cerebral Oxygenation and Perfusion Patterns}

\author{
Filipe Gonçalves Costa ${ }^{1,+} \oplus^{\mathbb{D}}$, Naser Hakimi ${ }^{1,2,+}$ and Frank Van Bel ${ }^{1, *}$ \\ 1 Department of Neonatology, University Medical Center Utrecht, 3584 EA Utrecht, The Netherlands; \\ fgervas2@umcutrecht.nl (F.G.C.); naser@artinis.com (N.H.) \\ 2 Artinis Medical Systems, B.V., 6662 PW Elst, The Netherlands \\ * Correspondence: f.vanbel@umcutrecht.nl; Tel.: +31-887-554-545 \\ + Shared first authorship.
}

check for updates

Citation: Costa, F.G.; Hakimi, N. Van Bel, F. Neuroprotection of the Perinatal Brain by Early Information of Cerebral Oxygenation and Perfusion Patterns. Int. J. Mol. Sci. 2021, 22, 5389. https://doi.org/ $10.3390 /$ ijms 22105389

Academic Editor: Olivier Baud

Received: 15 April 2021

Accepted: 17 May 2021

Published: 20 May 2021

Publisher's Note: MDPI stays neutral with regard to jurisdictional claims in published maps and institutional affiliations.

Copyright: (c) 2021 by the authors. Licensee MDPI, Basel, Switzerland. This article is an open access article distributed under the terms and conditions of the Creative Commons Attribution (CC BY) license (https:// creativecommons.org/licenses/by/ $4.0 /)$.

\begin{abstract}
Abnormal patterns of cerebral perfusion/oxygenation are associated with neuronal damage. In preterm neonates, hypoxemia, hypo-/hypercapnia and lack of cerebral autoregulation are related to peri-intraventricular hemorrhages and white matter injury. Reperfusion damage after perinatal hypoxic ischemia in term neonates seems related with cerebral hyperoxygenation. Since biological tissue is transparent for near infrared (NIR) light, NIR-spectroscopy (NIRS) is a noninvasive bedside tool to monitor brain oxygenation and perfusion. This review focuses on early assessment and guiding abnormal cerebral oxygenation/perfusion patterns to possibly reduce brain injury. In term infants, early patterns of brain oxygenation helps to decide whether or not therapy (hypothermia) and add-on therapies should be considered. Further NIRS-related technical advances such as the use of (functional) NIRS allowing simultaneous estimation and integrating of heart rate, respiration rate and monitoring cerebral autoregulation will be discussed.
\end{abstract}

Keywords: cerebral oxygenation monitoring; near infrared spectroscopy; neuroprotection; neuromonitoring; cerebral perfusion; cerebral autoregulation

\section{Introduction}

Reduction and prevention of perinatal brain damage focus, among other measures, mainly on stress reduction (preterm neonate), moderate hypothermia (term neonate) and pharmacological (add-on) therapy [1-3]. However, abnormal oxygenation and/or perfusion patterns often precede brain damage. The occurrence and extension of peri-intraventricular hemorrhages (PIVH) in very and extremely preterm infants (born between 28-32 weeks gestational age and below 28 weeks, respectively), whereas profound and persistent hypoxemia or hyperoxemia often precedes white matter injury (WMI) in this vulnerable group of neonates $[4,5]$. Likewise, in term neonates experiencing perinatal hypoxia-ischemia or birth asphyxia, (early) cerebral hyperoxygenation, loss of cerebral autoregulation and subsequent perfusion disturbances are related with additional brain damage and adverse 2-year outcome, or even death [6-8]. Early identification of erroneous cerebral oxygenation and/or perfusion patterns may therefore be important for timely corrective interventions, if possible, in order to prevent or at least reduce damage to the developing brain.

Biological tissue is transparent for the near infrared light part of the spectrum (700-1000 nm) and its subsequent absorption by oxygenated and deoxygenated hemoglobin makes (continuous-wave) near-infrared spectroscopy (NIRS) an ideal bedside tool to noninvasively monitor substantial changes in oxygenation and perfusion of the developing brain [9-12]. It actually measures the regional cerebral saturation $\left(\mathrm{rScO}_{2}\right)$ in a mixture of arterial, capillary and venous blood (normally in a ratio of $\sim 25 \sim 5 \sim 75 \%$, respectively) within the reach of the NIRS sensor attached to the skin of the head [9]. Typically, a banana-shaped area between emitting and receiving optodes is measured. The maximal penetration depth of the near infrared light is between 2 and $3 \mathrm{~cm}$, at least when the optodes distance is at 
least $4 \mathrm{~cm}$ [13]. It is expected that white and grey matter are both "insonated", at least in the preterm infants. This may be less straight forward when dealing with full-term infants. Oxygenation of the different brain regions seem to be quite homogeneous and did not substantially differ as investigated by us [14], suggesting that a single sensor placement is reliable to determine global $\mathrm{rScO}_{2}$. It is important to state that the clinically used NIRS devices monitor "trends" or changes in $\mathrm{rScO}_{2}$ rather than absolute values. Earlier studies showed that the precision of the commercially available devices is about $5.2 \%$ (ability to measure the same value after repeated measurement attempts) $[9,10,15]$. Moreover, there are sometimes quite significant differences in readings of $\mathrm{rSCO}_{2}$ by the various available devices based on different basic assumptions or algorithms [10,16]. It is widely accepted, though, that "normal" values of $\mathrm{rScO}_{2}$ in neonates are between $55-85 \%[17,18]$. In several experimental and clinical studies, it has been shown that sustained episodes of $\mathrm{rScO}_{2}$ values below $40-45 \%$ compromise oxygen metabolism of the developing brain and may cause neuronal damage [19-22].

Despite the reservations with respect to the exactness of NIRS-determined cerebral oxygenation we are of the opinion that "trend monitoring" of the oxygenation of the immature brain at the bedside in this noninvasive manner can be relevant for clinical care. The early recognition of (persistent) abnormal patterns of $\mathrm{rScO}_{2}$ values and NIRS-derived cerebral oxygen extraction may reflect derailment of cerebral oxygenation and perfusion $[15,23,24]$ and energetic and quick correction, if possible, may protect the immature brain.

In the next sections we will concentrate on the possible benefits for clinical care of early evaluation of the NIRS-monitored oxygen saturation signal (pattern recognition) in extremely preterm infants [15] and in term infants who experienced perinatal hypoxia and ischemia [8]. Further refinement such as integration with other monitoring parameters such as heart rate, respiratory rate and amplitude-integrated EEG (aEEG) will be briefly discussed, as well as the benefits of integration of the NIRS signal with blood pressure to assess (the lack of) cerebral autoregulation.

\section{Mechanisms of Brain Injury in the Preterm Infant and Cerebral Oxygenation}

In extremely preterm neonates, $\mathrm{PIVH}$ is one of the most important reasons for adverse (motor) developmental outcome and death, which has an incidence up to $45 \%$ in this population $[25,26]$. Mostly the bleedings are limited to the germinal matrix or with an additional moderate extension into the lateral cerebral ventricles (grade I and II, respectively, according to the Papile classification [27]). A minority evolves to larger PIVHs, grade III (large amount of blood in the cerebral ventricles which are dilated) or even extension of the blood into the brain parenchyma around the cerebral ventricles (grade IV or venous infarction). The etiology of PIVH is multifactorial and PIVHs developed perinatally and/or extended within $12 \mathrm{~h}$ after birth seem strongly associated with pro-inflammatory cytokines and formation of oxidative species [28,29]. However, most PIVHs develop and extend during the first 3 days of life or even later. The combination of vascular immaturity in the microcirculation of the germinal matrix [30] and often substantial increases (and fluctuations) in brain perfusion due to the respiratory distress syndrome (IRDS)-induced acutely increases in $\mathrm{pCO}_{2}$ and/or hypoxia [31,32], setting the brain for the development of PIVHs and their extension to more severe stages (i.e., grade III and IV) [28,33]. Important in this respect is that intravascular $\mathrm{CO}_{2}$ diffuses very quickly to the perivascular space of the cerebral resistance vasculature (contrary to bicarbonate: the blood-brain barrier is relatively impermeable to bicarbonate [34]), where it lowers the perivascular $\mathrm{pH}$, inducing acute vasodilation [32]. The fragile autoregulatory ability of the cerebral vascular bed in these extremely immature neonates is further provoked by the vasodilating effect of hypercarbia. This could result in a blood pressure-passive brain circulation contributing to fluctuations in the cerebral perfusion, possible episodes of hypoxia during hypotension and to extensions of already existing bleedings [35,36].

It may be clear that prevention or early recognition and down tuning of cerebral hyper(hypo-)perfusion/-oxygenation and/or a fluctuating pattern of the cerebral blood 
flow potentially reduce or even prevent the occurrence and extension of PIVHs. In this respect it is especially important to aim for a stable arterial carbon dioxide level within normal limits (i.e., $35-50 \mathrm{mmHg}$ ). Monitoring the pattern of cerebral oxygenation using NIRSdetermined $\mathrm{rScO}_{2}$ as early after birth as possible, preferably already on the resuscitation table, at least up to postnatal day 4 in these vulnerable group of neonates can alert the clinician at an early point in time for hypercapnia-induced hyperoxygenation/hyperperfusion [25,35] and hypoxia- or hypocapnia-induced underoxygenation/hypoperfusion [32] of the immature brain. A very recent study from Tamura et al. [37] showed that hypercapnia in the delivery room was associated with the occurrence of all grades of PIVH in a large cohort of preterm infants. Alderliesten et al. [35] showed supranormal $\mathrm{rScO}_{2}$ values [17] during $24 \mathrm{~h}$ preceding PIVH in a case-control study of 650 preterm infants below 32 gestational weeks. In the same study it was shown that the combination of hyperoxygenation (hyperperfusion) and loss of autoregulation preceded the extension of PIVHs to a higher grade. It was also reported that inotropes were related with loss of cerebral autoregulation (defined as a moving correlation $>0.5$ between $\mathrm{rScO}_{2}$ and mean arterial pressure). Other potentially more precise mathematical models to describe presence or absence of cerebral autoregulation such as coherence and transfer function gain are intensively investigated on their clinical relevance [38], which will be discussed in more detail in another section of this paper. A follow-up study at 15 and 24 months corrected age of a cohort of 734 preterm infants showed an association between low $\mathrm{rScO}_{2}$ values and adverse neurodevelopmental outcome at 2 years of age [39]. A recent prospective study in 185 extremely preterm neonates using NIRS-monitored $\mathrm{rScO}_{2}$ showed that prolonged cerebral desaturation was associated with the occurrence of any grade of PIVH [40]. So, early intervention to quickly normalize the arterial carbon dioxide, cerebral oxygen saturation levels, and prevention of large fluctuations in cerebral perfusion due to lack of autoregulatory ability of the cerebral vascular bed ("hands off" policy and/or sedation) will probably lower the PIVH incidence and its severity [41]. Up to now, only one prospective randomized intervention study in which in 166 preterm infants born after less than 28 weeks cerebral oxygenation was monitored with NIRS (study group) or not (control group) aiming to reduce episodes of hypo- or hyperoxia during the first 3 days of life [42]. It was reported that monitored infants, contrary to those infants whose monitors were blinded, lowered the burden of hypoxia and/or hyperoxia and showed a more stable cerebral oxygen saturation which was mostly within normal limits (55-85\%) [17]. This decreased the incidence of particularly severe PIVHs (grade III and IV) [43].

Although the incidence of cystic periventricular leukomalacia has greatly decreased in modern neonatal intensive care units, diffuse white matter injury (dWMI) occurs in about $50 \%$ of the extremely and very preterm infants according to MRI studies [44,45]. It has been suggested that an aborted maturation of the very vulnerable precursors of oligodendrocytes and by that arrest of myelination is responsible for the dWMI [46] and a very important reason for a suboptimal neurodevelopmental outcome of this patient group [47]. dWMI is often related to maternal and/or fetal infection or fetal hypoxia leading to proinflammatory cytokines and increased activity of microglia disturbing the development of oligodendrocyte precursors [48]. However, postnatal issues and in particular hypoxia with or without ischemia are also strongly related to dWMI. A relatively important role postnatally plays acute hypocapnia (and to a lesser extend hyperoxia) leading to instantaneous vasoconstriction of the cerebral vascular bed with consequent hypoperfusion, and thus lower oxygen delivery [5,32]. Especially abnormally low $\mathrm{rScO}_{2}$ values in a stable but artificially ventilated infant is suspicious for a ventilation-induced hypocapnia leading to ischemic-hypoxic damage of the immature brain [49]. The combination of NIRS-monitored cerebral oxygenation, arterial oxygen saturation, and end-tidal $\mathrm{CO}_{2}$ monitoring, increasingly used in standard clinical care in newborn intensive care units, might be a strong preventive policy against hypocapnia-induced WMI.

Some caution is also justified in case of a longstanding hemodynamically Patent Ductus Arteriosus (hsPDA), especially at present where an expectative policy with regard 
to (surgical) closure of the duct becomes mainstream [50,51]. A hsPDA gives rise to a ductal steal of blood originally destined for the brain with potential underperfusion/oxygenation of the developing immature brain and may not match metabolic demands [52]. In a study with a relatively large population of infants with hsPDA, we found abnormally low values of $\mathrm{rScO}_{2}$, often below $45 \%$ (so well below the lower limit of "normal" values of 55\% [17]). Persistent values lower than $40-45 \%$ are reported to be related with brain damage $[19,53]$. We indeed found an association between low cerebral oxygenation and duration of a hsPDA on the one hand and a lower volume of especially the cerebellum, a brain region with a remarkably high metabolism, on the other hand [53-55]. This finding confirmed earlier studies which reported negative effects of hsPDA on cerebellar growth in these immature neonates $[22,56]$. This suggests that longstanding hsPDAs may not always be as innocent as earlier believed. In our NICU all infants with signs of an hsPDA the cerebral oxygenation will be monitored for reasons as explained above.

The definition of "hypotension" of prematurity, mostly defined as a mean arterial pressure lower than the gestational age in weeks, gives way to overtreatment with positive inotropes. Several studies report the absence of signs of organ system dysfunction, metabolic acidosis or NIRS-monitored under-oxygenation of the brain during these "hypotensive" periods [35,57]. Moreover, long-term developmental outcome was not different compared to infants without hypotension $[57,58]$. At present our policy toward "hypotension" is expectative when NIRS-determined oxygenation of the brain is within normal limits with no signs of systemic under-perfusion or acidosis.

Other issues in which NIRS-monitored cerebral oxygenation can help to prevent injury to the immature brain are anemia and hypoglycemia: anemia with hemoglobin values below $6 \mathrm{mmol} / \mathrm{L}$ is reported to affect proper oxygenation of the preterm brain [59], whereas profound hypoglycemia can be recognized by spontaneously increasing levels of cerebral oxygenation due to depletion of glucose leading to a hampering of metabolism and hence oxygen utilization [60].

\section{Mechanisms of Brain Injury of the Term Infant and Cerebral Oxygenation}

Hypoxic-ischemic encephalopathy (HIE) due to perinatal asphyxia is a major cause of adverse neurodevelopmental outcome and neonatal mortality [61]. Although neuronal damage occurs during the actual (mostly fetal) hypoxic episode(s) due to excessive formation of excitatory neurotransmitters, profound calcium influx into the neuronal cells leading to acute oxidative damage to the cell membrane, a substantial part of birth asphyxiainduced brain injury occurs during the first 48 to $96 \mathrm{~h}$ of life and can even last for weeks and starts upon reperfusion and reoxygenation at birth [62]. Phosphorus nuclear magnetic resonance spectroscopy showed that during the first hours after reperfusion/reoxygenation upon birth cerebral oxidative metabolism is apparently normal, but secondary cerebral energy failure started after 10 to $12 \mathrm{~h}$ of age which seems to be maximal between 24 and $72 \mathrm{~h}$ of age leading to substantial additional brain injury [22,62]. Reoxygenation-induced production of free radicals, nitric monoxide and other toxic compounds give not only rise to acute damage to neuronal cells but also to activation of pro-inflammatory cytokine production leading to secondary cerebral energy failure and a decrease in trophic factors [63]. This delayed damage due to secondary energy failure, provides us with a "therapeutic" window in which reduction of brain damage can be achieved by preventing and/or scavenging free radical and nitrosative stress, important toxic substances contributing to secondary energy failure and concomitant brain damage. Until now, moderate hypothermia of the body down to $33.5^{\circ} \mathrm{C}$ for $72 \mathrm{~h}$ is the only established therapy reducing reperfusion damage after birth asphyxia. However, add-on therapy with (combinations of) pharmacologic neuroprotective compounds are currently investigated: It seems very likely that the combination of hypothermia with pharmacological compounds contribute to a further reduction of birth asphyxia related brain damage [63].

For an optimal reduction or even prevention of birth asphyxia-induced reoxygenationreperfusion damage of the developing brain, it is crucial to select infants that will benefit 
from postnatal treatment. This selection needs to be done as early as possible in this "therapeutic" window (alleged span of time first $6 \mathrm{~h}$ of life).

Abnormally high values of $\mathrm{rScO}_{2}(>80 \%)$ during the first 72 to $96 \mathrm{~h}$ of life in perinatally moderately and severely asphyxiated neonates, probably indicating less utilization of oxygen due to secondary energy failure and ongoing brain damage, are related with adverse long-term neurodevelopmental outcome with a high predictive value at as early as $3 \mathrm{~h}$ of life $[8,64,65]$. The pattern of $\mathrm{rScO}_{2}$ can, therefore, be an attractive noninvasive means to determine whether or not (add-on) neuroprotective therapy is necessary to reduce brain damage: although not properly investigated yet, a normalization of $\mathrm{rScO}_{2}$ values within normal limits upon (add-on) therapy may indicate a beneficial effect of treatment.

Since neuroimaging techniques such as cranial ultrasound, nowadays standard implemented in clinical care in the newborn intensive care unit, and (advanced) MRI of the neonatal brain improved substantially in the recent years, perinatal arterial ischemic stroke (PAIS) appeared to occur more often than previously reported and with an incidence of at least in 1:2300 newborns it is no longer a rare complication [66]. PAIS presents itself mostly in the first days after birth with seizures and can lead to cerebral paresis and to cognitive and motor impairments $[67,68]$. Neuroprotective/neuroregenerative therapeutic options were not existent up to recently and treatment was mostly limited to anti-epileptic therapy. However, nowadays potentially beneficial early neuroprotective intervention strategies are reported such as the use of neurotrophic substances such as erythropoietin and mesenchymal stem cells to boost neuro-regeneration [69,70].

Neuromonitoring, i.e., the combination of NIRS-monitored cerebral oxygenation and amplitude-integrated encephalography (aEEG), has an important prognostic value in PAIS [71]. Moreover, the early pattern of $\mathrm{rScO}_{2}$ and electrical background pattern and sleepwake cycling of the aEEG are probably useful in identifying neonates with PAIS who may benefit from neuroprotective interventions and for assessment of beneficial effects of these interventions [71]. $\mathrm{rScO}_{2}$ is substantially higher in the affected brain half as compared to the contralateral side, probably indicating luxury perfusion in the affected hemisphere [72,73]. The magnitude and duration of this difference was related with neurodevelopmental outcome [71]. Likewise, time to normal aEEG-derived electrical background (continuous normal voltage) of the affected brain half was longer as compared to the healthy brain half. The time to normalization of the electrical background pattern of the affected side was also related to neurodevelopmental outcome [71]. It is conceivable that neuroprotective interventions can shorten the duration of these asymmetries indicating a therapeutic effect. This assumption, however, remains to be investigated.

Table 1 summarizes the association between the nature of preterm and term acquired brain injuries on the one hand and the pattern of cerebral oxygenation on the other.

Table 1. Summary of associations between pathological substrate and pattern of cerebral oxygenation.

\begin{tabular}{|c|}
\hline Development/Extension of PIVH \\
\hline $\begin{array}{l}\text { - Hypercarbia-induced cerebral vasodilation: (abnormally) high } \mathrm{rScO}_{2} \\
\text { - } \quad \text { Lack of CAR: Blood pressure passive fluctuating pattern of } \mathrm{rScO}_{2}\end{array}$ \\
\hline (Cystic) Diffuse White Matter Injury \\
\hline $\begin{array}{l}\text { - Hypocarbia-induced cerebral vasoconstriction: (abnormally) } \mathrm{Low} \mathrm{rScO}_{2} \\
\text { - Hyperoxia-induced formation of cytokines / free rad: Low-to-normal } \mathrm{rScO}_{2} \\
\text { - } \text { hsPDA-related ductal steal of brain perfusion: prolonged episodes of low }(<45 \%) \mathrm{rScO}_{2} \\
\text { - Anemia-induced hypoxemia of the preterm brain: Low } \mathrm{rScO}_{2} \\
\text { - Hypoglycemia-related disturbance of glucose metabolism: increasing } \mathrm{rScO}_{2} \text { values }\end{array}$ \\
\hline Perinatal Ischemia-Hypoxia (Birth Asphyxia) \\
\hline - Secondary energy failure-induced: (abnormally) high $\mathrm{rScO}_{2}$ (from birth up to 72-96 h of age) \\
\hline Perinatal Arterial Ischemic Stroke \\
\hline $\begin{array}{l}\text { - Luxury perfusion-induced: higher } \mathrm{rScO}_{2} \text { in the ipsilateral hemisphere as compared to contralateral } \\
\text { hemisphere }\end{array}$ \\
\hline
\end{tabular}




\section{Future Perspectives of Multimodal Cerebral Oxygenation Monitoring: What Can It Add to Neuroprotection of the Perinatal Brain in the Clinical Setting?}

NIRS-derived monitoring of the cerebral oxygenation pattern in the preterm neonate and to a lesser extent also in the term neonate, has undeniable neuroprotective potential as showed above. However, applied research of NIRS-derived surveillance of oxygenation, cerebral perfusion and cerebral autoregulation is progressing quickly with the ultimate goal to improve clinical care.

In this perspective we want to discuss two important developments in perinatal NIRS research which may lead to clinical application in the near future: proper assessment of cerebral hemodynamics regulation which aims to couple systemic (hemodynamic and oxygenation) variables to NIRS signals; a more detailed analysis of NIRS-derived intensity signals for the surge to other usable physiological variables and artifacts detection is reviewed in Sections 5 and 6 below.

\section{Assessment of Cerebral Hemodynamics Regulation Using NIRS Signals}

In regard to cerebral hemodynamics regulation, one must take into account the mechanism of Cerebral Vascular Autoregulation (CVAR) - or pressure-flow reactivity. This property of the brain has the end goal of maintaining the cerebral blood flow at a constant level, regardless of the systemic blood pressure (BP) — but still within a limited range of $\mathrm{BP}$ values [74,75]. In the case of the BP going too low (or too high), the CVAR mechanism, through the arterioles, can no longer regulate the transmural pressure and the blood flow in the brain will, respectively, decrease or increase [76] (see Figure 1).

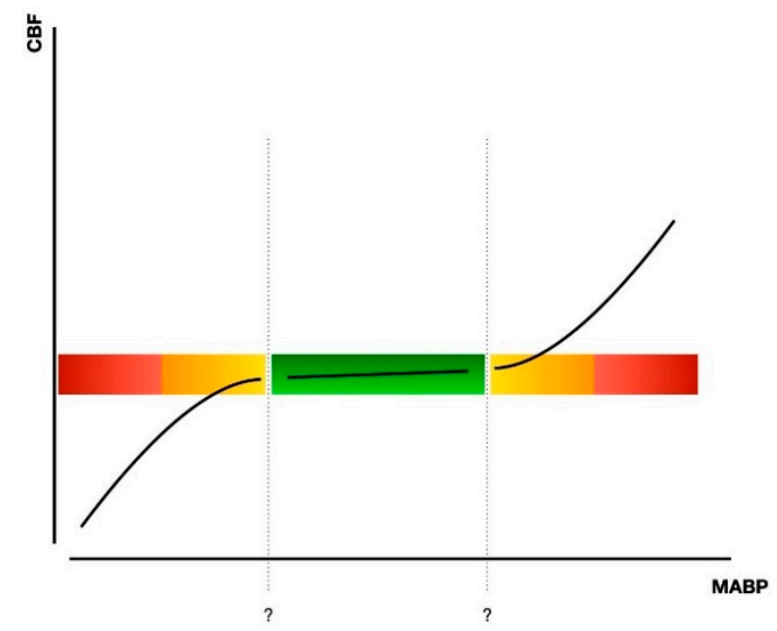

Figure 1. Autoregulatory curve of CBF variations according to mean arterial BP (MABP). In green, the ideal/healthy autoregulatory plateau, and in read/orange the extreme, and therefore dangerous areas of the plot.

Term infants have functional autoregulation and vasoreactivity, but preterm infants are born with an underdeveloped cerebral vascular system $[74,77]$. This is why the study of CVAR becomes relevant, when one takes into consideration the fact that (very) preterm infants are exposed to a higher risk of hemodynamic instability - and, therefore, brain damage-leading to PIVH or white matter injury [78] as also stated above. For this reason, online assessment and monitoring of the brain tissue oxygenation, combined with the state of the autoregulatory mechanism, is of utmost importance in the frontline of preventing brain injury and further neurodevelopmental disorders [39,79].

By evaluating the relation between $\mathrm{BP}$ and Cerebral Blood Flow (CBF) in a continuous way, it is possible to assess the mechanism of CVAR [75]. Since there is not a direct and non-invasive way to measure $\mathrm{CBF}$, and assuming a constant arterial oxygen saturation $\left(\mathrm{SaO}_{2}\right)$, the NIRS signal can be used as a surrogate for $\mathrm{CBF}$ changes, providing information on the oxygen saturation of the brain $\left(\mathrm{rScO}_{2}\right)[39,80,81]$. By observing the $\mathrm{rScO}_{2}$ signal it 
becomes possible to detect sudden changes and eventually relate them to variations in $\mathrm{BP}$, therefore identifying the presence or absence of the dynamics of autoregulation and providing us the possibility to interfere as already suggesting above [74].

The first steps into this analysis focus on the pre-processing stage, including filtering of the data, artifact removal and $\mathrm{SaO}_{2}$ correction [39]. Once this step is performed, there are two main approaches possible: analysis in the time domain or in the frequency domain. Time domain analysis calculates the correlation between the $\mathrm{BP}$ and $\mathrm{rScO}_{2}$ over short continuous segments, which can then be averages and distributed according to the corresponding BP values, thus having one correlation value per "bin" of blood pressure value [80,82-84]. Frequency domain analysis also explores the relation between these two signals, but with a focus on specific frequency bands [39]. This might come as an advantage when one considers that CVAR may be composed of responses with different time lags, therefore taking into account the delay between changes in $\mathrm{BP}$ and $\mathrm{rScO}_{2}$ [39]. One of these methods focuses on the Transfer Function (TF), analyzing the power spectral density (PSD) of the signals, which is a representation of the presence of each different frequency in the segments considered. From this, one can assess the TF gain, which indicates the impact that a change in the input signal (the BP) had in the output signal (the $\mathrm{rScO}_{2}$ ), and therefore assessing if CVAR was indeed present or not $[39,77]$. Another method of analysis is Coherence: this function measures the linearity of the two signals considered (BP and $\mathrm{rScO}_{2}$ ) in the frequency domain, indicating if there is a linear relationship between the input and the output of the system in focus $[39,76,77,80,84]$.

In all the methods described above, one must take into account the length of the epochs considered for analysis, as shorter epochs might produce noisier values-due to a smaller number of sub windows in the analysis-but epochs that are too long may indicate the presence of more nonstationary segments than the ones regarding CVAR, and, therefore, producing lower values and hindering the results [84]. Another factor from the clinical care point of view is that it is important to have in mind that these methods require signals that are continuous and stable enough to provide trustworthy results [85].

We, therefore, must always aim for a stable CVAR mechanism, even though there is still a lack of agreement as to what the best method for analysis is, as well as a proper online monitoring method at the bedside.

Despite the methods presented above, a global consensus is still lacking, as the ideal (online) system should be easily reproducible regardless of the population in focus and the preterm age. Ongoing research of CVAR assessment should also focus on the demonstration of a globally accepted tool or method that monitors $\mathrm{CBF}$ and $\mathrm{rScO}_{2}$, confirming the relation of the changes in those signals with neurodevelopmental outcome [76].

\section{NIRS-Derived Intensity Signals and the Importance of Signal Quality Assessment}

Using the NIRS technique, different information can be acquired from the intensity of the light measured by the receivers. As stated above cerebral oxygenation $\left(\mathrm{rScO}_{2}\right)$ is the most common information acquired when using NIRS in clinical applications. However, the NIRS-derived intensity signals provide, apart from estimating the cerebral oxygenation, some useful additional functional and physiological information. The intensity signals can be converted into concentration changes in oxygenated hemoglobin $\left(\mathrm{O}_{2} \mathrm{Hb}\right)$ and deoxygenated hemoglobin $(\mathrm{HHb})$ [86], which can be used to determine brain hemodynamic response in different brain regions [86-88]. The intensity and concentration signals contain some physiological information including cardiac pulsation, respiration, and vasomotor action [89-92]. Figure 2 shows an example of the $\mathrm{O}_{2} \mathrm{Hb}$ and $\mathrm{HHb}$ signals, in which the heartbeats are visibly seen with approximately 0.4 -s time intervals, together with the $\mathrm{rScO}_{2}$ measured by Artinis cerebral oximetry device (TOM, Artinis Medical Systems B.V., Elst, The Netherlands). 


\subsection{NIRS-Derived Heartbeat Pattern}

The most prominent physiological information in NIRS signals are the pulsatile fluctuations caused by heartbeats and will be discussed here. This Information in the NIRS signals allows for the extraction of heart rate (HR). Several studies have shown the compatibility of the HR derived from NIRS with the HR extracted from electrocardiography and photoplethysmography [93-95]. Moreover, the HR derived from NIRS has shown to be a richer source of information than HR derived from PPG or ECG under physical and mental stressful conditions [92,94-96]. Deriving HR from NIRS signals is highly useful in neonates as it can eliminate the need to use extra electrode for recording this information [97]. Eliminating extra electrodes can relieve neonates from physical stresses induced by electrode placement and potentially reduces injury risks [98].

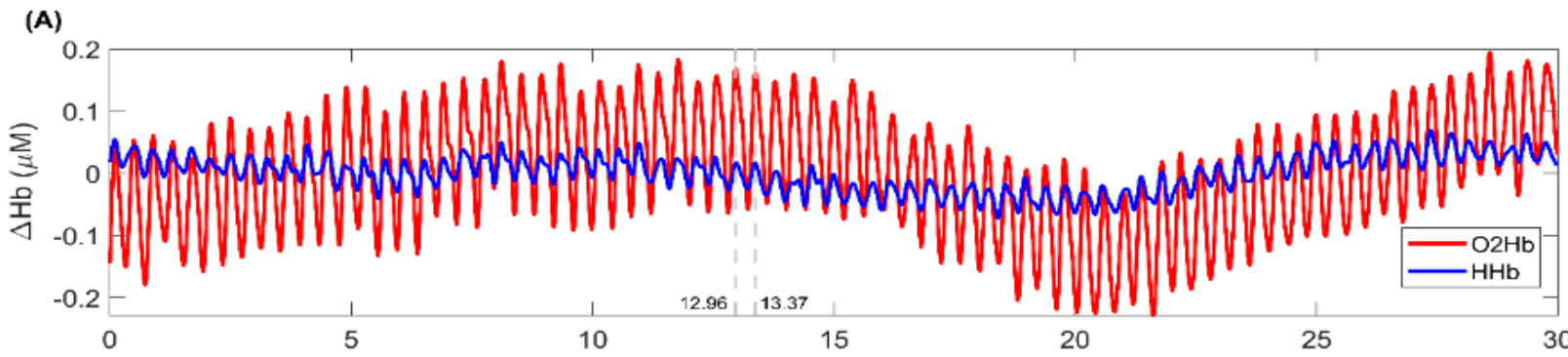

(B)

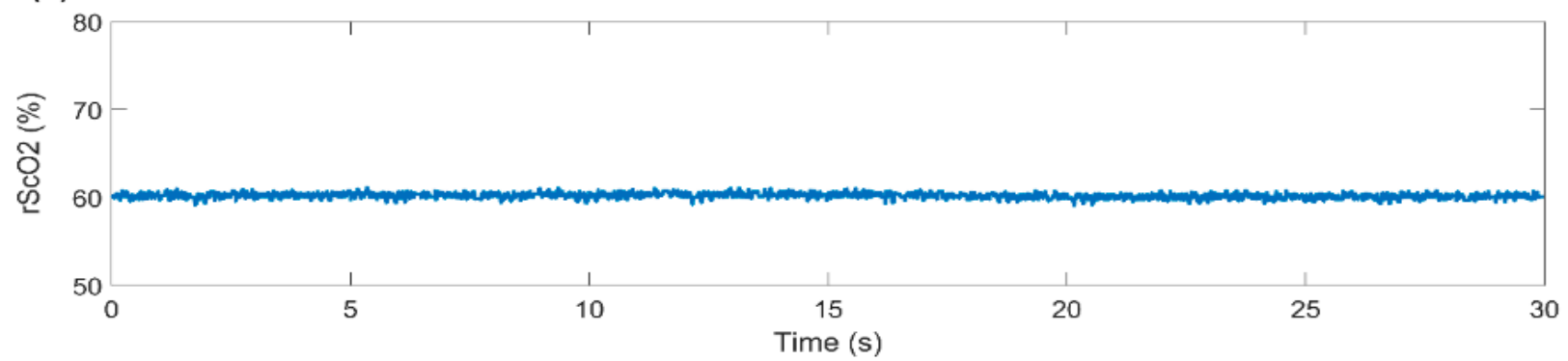

Figure 2. An example of the NIRS signals recorded by the TOM device (Artinis Medical Systems B.V., Elst, The Netherlands). (A) Concentration changes in oxygenated hemoglobin $\left(\mathrm{O}_{2} \mathrm{Hb}\right)$ and deoxygenated hemoglobin $(\mathrm{HHb})$ in red and blue, respectively. These signals have been detrended to have a similar baseline. The heartbeats are visible in both signals as pulsatile changes with approximately 0.4-s time interval. (B) The cerebral tissue oxygenation, $\mathrm{rScO}_{2}$, computed by the TOM device in percentage. The signals are sampled at $100 \mathrm{~Hz}$.

The HR and brain hemodynamic information in the NIRS signals can be fused in different applications where both brain and heart functions are altered. For instance, they can be combined to accurately assess (physical) stress [92,94,97]. Furthermore, extracting the HR information from NIRS can reduce the ambiguity of the hemodynamic response model [96,99-101]. The extracted HR information can be used as a known physiological term in a part of the model representing different physiological components in the NIRS signal. This can ameliorate the hemodynamic response model and enhance the accuracy of brain hemodynamic response estimation in the clinical setting.

\subsection{Signal Quality Assessment}

In NIRS techniques, the NIR light travels through different tissue layers including intra- and extracranial layers before it strikes the brain. Some factors in the extracranial layer directly affect the optical pathway of the transmitted light. For example, scalp thickness, skin properties, and the presence and color of hair can disrupt the light passing through the head [102,103]. As a consequence, the coupling between NIRS sensors and scalp is decreased, and the NIRS signal quality is then deteriorated [104]. This may result in wrong interpretations and consequent false findings in the analyses. Therefore, assessing 
the quality of the NIRS signals before analyzing the signals is important that can increase the reliability of the statistical analysis and decrease misinterpretations.

To assess NIRS signal quality, the presence of a strong cardiac component has been often used as the main indicator of a reliable sensor-scalp coupling [105-108]. A reliable sensor-scalp coupling guarantees that NIR light travels through both intra- and extracranial layers. As a result, the received light (NIRS signals) contains brain hemodynamic and physiological information from both layers. Therefore, the presence of heartbeat, the most prominent systemic information in NIRS signals, indicates that sensors have been well coupled to the scalp and that enough light strikes the brain and is backscattered to the receiver. This knowledge will greatly improve the reliability of the NIRS signal and hence its clinical use.

\section{Conclusions}

Wide-scale utilization of NIRS-derived monitoring of cerebral oxygenation based on timely recognition of an abnormal pattern of cerebral oxygenation seems a relatively straightforward means for prevention and/or reduction of brain injury in very and extremely preterm neonates (i.e., PIVH and dWMI) and to a lesser extent also in the term asphyxiated neonate. Despite this it is very important that the precision of NIRS monitored cerebral oxygen saturation further increases. Equally important is the extended research of NIRS signals to reliably monitor CVAR and the use of the NIRS signal (quality and diversity) to monitor also hemodynamic functions, which contributes to a more informed decision on whether or not to handle the infant at a certain time. These developments may further contribute to the prevention of perinatal brain damage. International collaboration and unified definitions are important to increase utilization of NIRS as a potentially neuroprotective strategy.

Author Contributions: Conceptualization: F.V.B.; Writing-original draft preparation: F.V.B., F.G.C. and N.H.; Writing-review and editing: F.V.B., F.G.C. and N.H.; All authors have read and agreed to the published version of the manuscript.

Funding: This research received no external funding.

Institutional Review Board Statement: Not applicable.

Informed Consent Statement: Not applicable.

Conflicts of Interest: The authors declare no conflict of interest. Filipe Gonçalves Costa and Naser Hakimi are both part of the EU H2020 MSCA-ITN-2018: INtegrating Functional Assessment measures for Neonatal Safeguard (INFANS), funded by the European Commission under Grant Agreement \#813483. Naser Hakimi is also employed by Artinis Medical Systems B.V., Elst, The Netherlands.

\section{References}

1. van Bel, F.; Vaese, J.; Groenedaal, F. Prevention, reduction and repair of brain injury of the preterm infant. Front. Physiol. 2019. [CrossRef]

2. Jacobs, S.E.; Berg, M.; Hunt, R.; Tarnow-Mordi, W.O.; Inder, T.E.; Davis, P.G. Cooling for newborns with hypoxic ischaemic encephalopathy. Cochrane Database. Cochrane Database Syst. Rev. 2013, 1. [CrossRef]

3. van Bel, F.; Groenendaal, F. Drugs for neuroprotection after birth asphyxia: Pharmacologic adjuncts to hypothermia. Semin. Perinatol. 2016, 40, 152-159.

4. Perlman, J.M.; McMenamin, J.B.; Volpe, J.J. Fluctuating cerebral blood flow velocity in respiratory-distress syndrome. Relation to the development to the development of intraventricular hemorrhage. N. Engl. J. Med. 1983, 309, 204-209. [CrossRef]

5. Shankaran, S.; Langer, J.C.; Kazzi, S.N.; Laptook, A.R.; Walsh, M. Cumulative index of exposure to hypocarbia and hyperoxia as risk factors for periventricular leukomalacia in low birth weight infants. Pediatrics 2006, 118, 1654-1659. [CrossRef]

6. Greisen, G. Cerebral blood flow and oxygenation in infants after birth asphyxia. Clinically useful information? Early Hum. Dev. 2014, 90, 703-705. [CrossRef] [PubMed]

7. Howlett, J.A.; Northington, F.J.; Gilmore, M.M.; Tekes, A.; Huisman, T.A.; Parkinson, C.; Chung, S.E.; Jennings, J.M.; Jamrogowicz, J.J.; Larson, A.C.; et al. Cerebral autoregulation and neurologic injury in neonatal hypoxic-ischemic encephalopathy. Pediatric Res. 2013, 74, 525-535. [CrossRef] [PubMed] 
8. Lemmers, P.M.; Zwanenburg, R.J.; Benders, M.J.; de Vries, J.S.; Groenendaal, F.; van Bel, F.; Toet, M. Cerebral oxygenation and brain activity after perinatal asphyxia: Does hypothermia change their prognostic value? Pediatric Res. 2013, 74, 180-185. [CrossRef]

9. Van Bel, F.; Lemmers, P.; Naulaers, G. Monitoring neonatal regional cerebral oxygen saturation in clinical practice: Value and pitfalls. Neonatology 2008, 94, 237-244. [CrossRef]

10. Greisen, G.; Andresen, B.; Plomgaard, A.M.; Hyttel-Sørensen, S. Cerebral oximetry in preterm infants: An agenda for research with a clear clinical goal. Neurophotonics 2016, 3, 31407. [CrossRef]

11. Skov, L.; Pryds, O.; Greisen, G. Estimating Cerebral Blood Flow in Newborn Infants: Comparison of Near Infrared Spectroscopy and 133Xe Clearance. Pediatric Res. 1991, 30, 570-573. [CrossRef] [PubMed]

12. Alderliesten, T.; De Vis, J.B.; Lemmers, P.M.; Hendrikse, J.; Groenendaal, F.; Van Bel, F.; Benders, M.J.; Petersen, E.T. Brain oxygen saturation assessment in neonates using T2-prepared blood imaging of oxygen saturation and near-infrared spectroscopy. Br. J. Pharm. 2017, 37, 902-913. [CrossRef]

13. Greisen, G. Is near-infrared spectroscopy living up to its promises? Semin. Fetal Neonatal Med. 2006, 11, 498-502. [CrossRef] [PubMed]

14. Wijbenga, R.G.; Lemmers, P.M.; van Bel, F. Cerebral oxygenation during the first days of life in preterm and term neonates: Dif-ferences between different brain regions. Pediatr. Res. 2011, 70, 389-394. [CrossRef] [PubMed]

15. Bel, V.; Mintzer, J. Monitoring cerebral oxygenation of the immature brain: A neuroprotective strategy? Pediatr. Res. 2018, 84, 159-164.

16. Dix, L.M.; Van Bel, F.; Baerts, W.; Lemmers, P.M. Comparing near-infrared spectroscopy devices and their sensors for monitoring regional cerebral oxygen saturation in the neonate. Pediatr. Res. 2013, 74, 557-563. [CrossRef] [PubMed]

17. Alderliesten, T.; Dix, L.; Baerts, W.; Caicedo, A.; Van Huffel, S.; Naulaers, G.; Groenendaal, F.; Van Bel, F.; Lemmers, P. Reference values of regional cerebral oxygen saturation during the first 3 days of life in preterm neonates. Pediatr. Res. 2016, 79, 55-64. [CrossRef]

18. Pellicer, A.; Greisen, G.; Benders, M.; Claris, O.; Dempsey, E.; Fumagally, M.; Gluud, C.; Hagmann, C.; Hellström-Westas, L.; Hyttel-Sorensen, S.; et al. The SafeBoosC phase II randomized clinical trial: A treatment guideline for targeted near-infrared derived cerebral tissue oxygenation versus standard treatment in extremely preterm in-fants. Neonatology 2013, 104, 171-178. [CrossRef] [PubMed]

19. Hou, X.; Ding, H.; Teng, Y.; Zhou, C.; Tang, X.; Li, S.; Ding, H. Research on the relationship between brain anoxia at different regional oxygen saturations and brain damage using near-infrared spectroscopy. Physiol. Meas. 2007, 28, 1251-1265. [CrossRef]

20. Kurth, C.D.; McCann, J.C.; Wu, J.; Miles, L.; Loepke, A.W. Cerebral Oxygen Saturation-Time Threshold for Hypoxic-Ischemic Injury in Piglets. Anesth. Analg. 2009, 108, 1268-1277. [CrossRef]

21. Dent, C.L.; Spaeth, J.P.; Jones, B.V.; Schwartz, S.M.; Glauser, T.A.; Hallinan, B.; Pearl, J.M.; Khoury, P.R.; Kurth, C.D. Brain magnetic resonance imaging abnormalities after the Norwood procedure using regional cerebral perfusion. J. Thorac. Cardiovasc. Surg. 2006, 131, 190-197. [CrossRef]

22. Kusaka, T.; Ueno, M.; Miki, T.; Kuboi, T.; Nakamura, S.; Koyano, K.; Ijichi, S.; Yasuda, S.; Okubo, K.; Kawada, K.; et al. Relationship between cerebral oxygenation and phosphorylation potential during second-ary energy failure in hypoxic-ischemic newborn piglets. Pediatr. Res. 2009, 65, 317-322. [CrossRef] [PubMed]

23. Wintermark, P.; Hansen, A.; Warfield, S.K.; Dukhovny, D.; Soul, J.S. Near-infrared spectroscopy versus magnetic resonance im-aging to study brain perfusion in newborns with hypoxic-ischemic encephalopathy treated with hypothermia. Neuroimage 2014, 85, 287-293. [CrossRef] [PubMed]

24. Arman, D.; Sancak, S.; Gürsoy, T.; Topcuoğlu, S.; Karatekin, G.; Ovalı, F. The association between NIRS and Doppler ultrasonography in preterm infants with patent ductus arteriosus. J. Matern. Fetal Neonatal Med. 2019, 33, 1245-1252. [CrossRef]

25. Volpe, J.J. Neurology of the Newborn, 6th ed.; Elsevier: Philadelphia, PA, USA, 2018; pp. 325-698.

26. Hollebrandse, N.L.; Spittle, A.J.; Burnett, A.C.; Anderson, P.J.; Roberts, G.; Doyle, L.W.; Cheong, J.L.Y. School-age outcomes following intra-ventricular haemorrhages in infants born extremely preterm. Arch. Dis. Child. Fetal Neonatal Ed. 2021, 106, 4-8. [CrossRef]

27. Papile, L.A.; Burstein, J.; Burstein, R.; Koffler, H. Incidence and evolution of subependymal and intraventricular hemorrhage: A study of infants with birth weights less than 1500 gm. J. Pediatr. 1978, 92, 529-534. [CrossRef]

28. Krediet, T.G.; Kavelaars, A.; Vreman, H.J.; Heijnen, C.J.; van Bel, F. Respiratory distress syndrome-associated inflammation is re-lated to early but not late peri/intraventricular hemorrhage in preterm infants. J. Pediatr. 2006, 148, 740-746. [CrossRef]

29. Villamor-Martinez, E.; Fumagalli, M.; Rahim, O.M.; Passera, S.; Cavallaro, G.; Degraeuwe, P.; Mosca, F.; Villamor, E. Chorioamnionitis Is a Risk Factor for Intraventricular Hemorrhage in Preterm Infants: A Systematic Review and Meta-Analysis. Front. Physiol. 2018, 9, 1253. [CrossRef]

30. Ballabh, P. Pathogenesis and Prevention of Intraventricular Hemorrhage. Clin. Perinatol. 2014, 41, 47-67. [CrossRef]

31. Kontos, H.A.; Raper, A.H.; Patterson, J.L., Jr. Analysis of vasoactivity of local pH, PCO2, and bicarbonate on cat pial arterioles. Stroke 1977, 8, 226-234. [CrossRef]

32. Dix, L.M.L.; Weeke, L.C.; de Vries, L.S.; Groenendaal, F.; Baerts, W.; van Bel, F.; Lemmers, P.M.A. Carbon dioxide fluctuations are asso-ciated with changes in cerebral oxygenation and electrical activity in infants born preterm. J. Pediatr. 2017. [CrossRef] [PubMed] 
33. van Bel, F.; Van de Bor, M.; Stijnen, T.; Baan, J.; Ruys, J.H. Aetiological role of cerebral blood-flow alterations in development and extension of peri-intraventricular haemorrhage. Dev. Med. Child. Neurol. 1987, 29, 601-614.

34. Maren, T.H. Effect of varying CO2 equilibria on rates of HCO3- formation in cerebrospinal fluid. J. Appl. Physiol. Respir. Env. Exerc. Physiol. 1979, 47, 471-480. [CrossRef]

35. Alderliesten, T.; Lemmers, P.M.A.; Smarius, J.J.M.; van de Vosse, R.E.; Baerts, W.; van Bel, F. Cerebral oxygenation, extraction, and autoregulation in very preterm infants who develop peri-intraventricular haemorrhage. J. Pediatr. 2013, 162, 698-704. [CrossRef] [PubMed]

36. Hoffman, S.B.; Cheng, Y.J.; Magder, L.S.; Shet, N.S. Cerebral autoregulation in premature infants and relationship to adverse out-come. Arch. Dis. Child. Fetal Neonatal Ed. 2018. [CrossRef]

37. Tamura, K.; Williams, E.E.; Dassios, T.; Pahuja, A.; Hunt, K.A.; Murthy, V.; Bhat, P.; Bhat, R.; Milner, A.; Greenough, A. End-tidal carbon dioxide levels during resuscitation and carbon dioxide levels in the immediate neonatal period and intraventricular hemorrhage. Eur. J. Pediatr. 2020, 179, 555-559. [CrossRef] [PubMed]

38. Thewissen, L.; Caicedo, A.; Lemmers, P.; Van Bel, F.; Van Huffel, S.; Naulaers, G. Measuring Near-Infrared Spectroscopy Derived Cerebral Autoregulation in Neonates: From Research Tool Toward Bedside Multimodal Monitoring. Front. Pediatr. 2018, 6. [CrossRef] [PubMed]

39. Alderliesten, T.; van Bel, F.; van der Aa, N.; Steendijk, P.; van Haastert, I.; de Vries, L.S.; Groenendaal, F.; Lemmers, P. Low cerebral oxygenation in preterm infants is associated with adverse neurodevelopmental outcome. J. Pediatr. 2019, 207, 109-116. [CrossRef]

40. Vesoulis, Z.A.; Whitehead, H.V.; Liao, S.M.; Mathur, A.M. The hidden consequence of intraventricular hemorrhage: Persistent cer-ebral desaturation after IVH in preterm infants. Pediatric Res. 2020. [CrossRef]

41. Hoffman, S.B.; Cheng, Y.J.; Magder, L.S.; Shet, N.; Viscardi, R.M. Cerebral autoregulation in premature infants dueing the first 96 hours of life and relationship to adverse outcomes. Arch. Dis. Child. Fetal Neonatal Ed. 2018, 104, 473-479. [CrossRef]

42. Hyttel-Sorensen, S.; Pellicer, A.; Alderliesten, T.; Austin, T.; Van Bel, F.; Benders, M.; Claris, O.; Dempsey, E.; Franz, A.R.; Fumagalli, M.; et al. Cerebral near infrared spectroscopy oximetry in extremely preterm infants: Phase II randomised clinical trial. BMJ 2015, 350, 7635. [CrossRef] [PubMed]

43. Plomgaard, A.M.; Alderliesten, T.; Austin, T.; Van Bel, F.; Benders, M.; Claris, O.; Dempsey, E.M.; Fumagalli, M.; Gluud, C.; Hagmann, C.; et al. Early biomarkers of brain injury and cerebral hypo- and hyperoxia in the SafeBoosC II trial. PLoS ONE 2017, 12, e0173440. [CrossRef]

44. Volpe, J.J. Brain injury in premature infants: A complex amalgam of destructive and developmental disturbances. Lancet Neurol. 2009, 8, 110-124. [CrossRef]

45. Chau, V.; Synnes, A.; Grunau, R.E.; Poskitt, K.J.; Brant, R.; Miller, S.P. Abnormal brain maturation in preterm neonates associated with ad-verse outcome. Neurology 2013, 81, 2082-2089. [CrossRef]

46. Van Tilborg, E.; de Theije, C.G.M.; van Hal, M.; Wagenaar, N.; de Vries, L.S.; Benders, M.J.; Rowitch, D.H.; Nijboer, C.H. Origin and dynamics of oligoden-drocytes in the developing brain. Glia 2018, 66, 221-238. [CrossRef]

47. Brouwer, M.J.; Kersbergen, K.J.; Van Kooij, B.J.M.; Benders, M.J.N.L.; Van Haastert, I.C.; Koopman-Esseboom, C.; Neil, J.J.; De Vries, L.S.; Kidokoro, H.; Inder, T.E.; et al. Preterm brain injury on term-equivalent age MRI in relation to perinatal factors and neurodevelopmental outcome at two years. PLoS ONE 2017, 12, e0177128. [CrossRef]

48. Favrais, G.; Van De Looij, Y.; Fleiss, B.; Ramanantsoa, N.; Bonnin, P.; Stoltenburg-Didinger, G.; Lacaud, A.; Saliba, E.; Dammann, O.; Gallego, J.; et al. Systemic inflammation disrupts the developmental program of white matter. Ann. Neurol. 2011, 70, 550-565. [CrossRef]

49. Greissen, G.; Vannucci, R.C. Is periventricular leukomalacia a result of hypoxic-ischaemic injury? Hypocapnia and the pre-term brain. Newborn High Risk Brain Damage 2001, 79, 194-200.

50. Benitz, W.E. Treatment of persistent patent ductus arteriosus in preterm infants: Time to accept the null hypothesis? J. Perinatol. 2010, 30, 241-252. [CrossRef]

51. Noori, S. Patent ductus arteriosus in the preterm infant: To treat or not to treat? J. Perinatol. 2010, 30, S31-S37. [CrossRef]

52. Giesinger, R.E.; McNamara, P.J. Hemodynamic instability in the critically ill neonate: An approach to cardiovascular support based on disease pathophysiology. Semin. Perinatol. 2016, 40, 174-188. [CrossRef] [PubMed]

53. Lemmers, P.M.; Benders, M.J.; D'Ascenzo, R.; Zethof, J.; Alderliesten, T.; Kersbergen, K.J.; Isgum, I.; de Vries, L.S.; Groenendaal, F.; van Bel, F. Patent Ductus Arteriosus and Brain Volume. Pediatrics 2016, 137, e20153090. [CrossRef] [PubMed]

54. Volpe, J.J. Cerebellum of the Premature Infant: Rapidly Developing, Vulnerable, Clinically Important. J. Child. Neurol. 2009, 24, 1085-1104. [CrossRef]

55. Witter, L.; Rudolph, S.; Pressler, R.T.; Lahlaf, S.I.; Regehr, W.G. Purkinje Cell Collaterals Enable Output Signals from the Cerebellar Cortex Report Feed Back to Purkinje Cells and Interneurons. Neuron 2016, 91, 312-319. [CrossRef]

56. Limperopoulos, C.; Benson, C.B.; Bassan, H.; Disalvo, D.N.; Kinnamon, D.D.; Moore, M.; Ringer, S.A.; Volpe, J.J.; Plessis, A.J. Cerebellar hemorrhage in the preterm infant: Ultrasonographic findings and risk factors. Pediatrics 2005, 116, 717-724. [CrossRef] [PubMed]

57. Alderliesten, T.; Lemmers, P.M.A.; van Haastert, I.C.; de Vries, L.S.; Bonestroo, H.J.C.; Baerts, W.; van Bel, F. Hypotension in preterm neonates: Low blood pressure alone does not affect neurodevelopmental outcome. J. Pediatr. 2014, 164, 986-991. [CrossRef] 
58. Dempsey, E.M.; Al Hazzani, F.; Barrington, K.J. Permissive hypotension in the extremely low birth weight infant with signs of good perfusion. Arch. Dis. Child. Fetal Neonatal Ed. 2009, 94, F241-F244. [CrossRef]

59. Van Hoften, J.C.; Verhagen, E.A.; Keating, P.; ter Horst, H.J.; Bos, A.F. Cerebral tissue oxygen saturation and extraction in preterm infants before and after blood transfusion. Arch. Dis. Child. Fetal Neonatal Ed. 2010, 95, F352-F358. [CrossRef]

60. Vanderhaegen, J.; Vanhaesebrouck, S.; Vanhole, C.; Casaer, P.; Naulaers, G. The effect of glycaemia on the cerebral oxygenation in very low birth weight infants as measured by near-infrared spectroscopy. Adv. Exp. Mex Biol. 2010, 662, 461-464.

61. Liu, L.; Johnson, H.L.; Cousens, S.; Perin, J.; Scott, S.; Lawn, J.E.; Rudan, I.; Campbell, H.; Cibulskis, R.; Li, M.; et al. Child health epidemiology reference group of WHO and UNICEF Global, regional, and national causes of child mortality in 2008: A systemic analysis. Lancet 2010, 375, 1969-1987.

62. Lorek, A.; Takei, Y.; Cady, E.B.; Wyatt, J.S.; Penrice, J.; Edwards, A.D.; Peebles, D.; Wylezinska, M.; Owen-Reece, H.; Kirkbride, V.; et al. Delayed ("Secondary") Cerebral Energy Failure after Acute Hypoxia-Ischemia in the Newborn Piglet: Continuous 48-Hour Studies by Phosphorus Magnetic Resonance Spectroscopy. Pediatr. Res. 1994, 36, 699-706. [CrossRef] [PubMed]

63. Groenendaal, F.; Benders, M.J.N.L.; de Vries, L.S.; van Bel, F. Neuroprotective drugs and perinatal brain injury. In Neonatal and Pediatric Pharmacology: Therapeutic Principles in Practice, 5th ed.; Aranda, J.V., van den Anker, J.N., Eds.; Wolter Kluwer Pub-Licers: Philadelphia, PA, USA, 2021; pp. 171-182.

64. Toet, M.C.; Lemmers, P.M.; van Schelven, L.J.; van Bel, F. Cerebral oxygenation and electrical activity after birth asphyxia: Their relation to outcome. Pediatrics 2006, 117, 333-339. [CrossRef] [PubMed]

65. Ancora, G.; Maranella, E.; Grandi, S.; Sbravati, F.; Coccolini, E.; Savini, S.; Faldella, G. Early predictors of short term neurodevelopmental outcome in asphyxiated cooled infants. A combined brain amplitude integrated electroencephalography and near infrared spectroscopy study. Brain Dev. 2013, 35, 26-31. [CrossRef]

66. Lynch, J.K. Epidemiology and classification of perinatal stroke. Semin. Fetal Neonatal Med. 2009, 14, 245-249. [CrossRef]

67. Fernández-López, D.; Natarajan, N.; Ashwal, S.; Vexler, Z.S. Mechanisms of Perinatal Arterial Ischemic Stroke. J. Cereb. Blood Flow Metab. 2014, 34, 921-932. [CrossRef] [PubMed]

68. Wagenaar, N.; Martinez-Biarge, M.; Van Der Aa, N.E.; Van Haastert, I.C.; Groenendaal, F.; Benders, M.J.; Cowan, F.M.; De Vries, L.S. Neurodevelopment After Perinatal Arterial Ischemic Stroke. Pediatrics 2018, 142, e20174164. [CrossRef] [PubMed]

69. Benders, M.J.; van der Aa, N.E.; Roks, M.; van Straaten, H.L.; Isgum, I.; Viergever, M.A.; Groenendaal, F.; de Vries, L.S.; van Bel, F. Feasibility and Safety of Erythropoietin for Neuroprotection after Perinatal Arterial Ischemic Stroke. J. Pediatr. 2014, 164, 481-486.e2. [CrossRef]

70. Wagenaar, N.; De Theije, C.G.M.; De Vries, L.S.; Groenendaal, F.; Benders, M.J.N.L.; Nijboer, C.H. Promoting neuroregeneration after perinatal arterial ischemic stroke: Neurotrophic factors and mesenchymal stem cells. Pediatr. Res. 2018, 83, 372-384. [CrossRef]

71. Wagenaar, N.; Berk, D.J.V.D.; Lemmers, P.M.; Van Der Aa, N.E.; Dudink, J.; Van Bel, F.; Groenendaal, F.; De Vries, L.S.; Benders, M.J.; Alderliesten, T. Brain Activity and Cerebral Oxygenation After Perinatal Arterial Ischemic Stroke Are Associated With Neurodevelopment. Stroke 2019, 50, 2668-2676. [CrossRef]

72. Wintermark, P.; Warfield, S.K. New insights in perinatal arterial ischemic stroke by assessing brain perfusion. Transl. Stroke Res. 2012, 3, 255-262. [CrossRef]

73. Van der Aa, N.E.; Porsius, E.D.; Hendrikse, J.; van Kooij, B.J.M.; Benders, M.J.N.L.; de Vries, L.S.; Groenendaal, F. Changes in carotid blood flow after unilateral arterial ischemic stroke. Pediatr. Res. 2012, 72, 50-56. [CrossRef]

74. Greisen, G. Autoregulation of cerebral blood flow in newborn babies. Early Hum. Dev. 2005, 81, 423-428. [CrossRef]

75. Caicedo, A.; De Smet, D.; Vanderhaegen, J.; Naulaers, G.; Wolf, M.; Lemmers, P.; Van Bel, F.; Ameye, L.; Van Huffel, S. Impaired Cerebral Autoregulation Using Near-Infrared Spectroscopy and Its Relation to Clinical Outcomes in Premature Infants. Adv. Exp. Med. Biol. 2011, 701, 233-239. [CrossRef]

76. El-Dib, M.; Soul, J.S. Monitoring and management of brain hemodynamics and oxygenation. Handb. Clin. Neurol. 2019, 162, 295-314. [CrossRef] [PubMed]

77. Rhee, C.J.; Da Costa, C.S.; Austin, T.; Brady, K.M.; Czosnyka, M.; Lee, J.K. Neonatal cerebrovascular autoregulation. Pediatr. Res. 2018, 84, 602-610. [CrossRef] [PubMed]

78. Chock, V.Y.; Kwon, S.H.; Ambalavanan, N.; Batton, B.; Nelin, L.D.; Chalak, L.F.; Tian, L.; Van Meurs, K.P. Cerebral Oxygenation and Autoregulation in Preterm Infants (Early NIRS Study). J. Pediatr. 2020, 227, 94-100. [CrossRef]

79. Massaro, A.N.; Govindan, R.B.; Vezina, G.; Chang, T.; Andescavage, N.N.; Wang, Y.; Al-Shargabi, T.; Metzler, M.; Harris, K.; Du Plessis, A.J. Impaired cerebral autoregulation and brain injury in newborns with hypoxic-ischemic encephalopathy treated with hypothermia. J. Neurophysiol. 2015, 114, 818-824. [CrossRef] [PubMed]

80. Vesoulis, Z.A.; Mathur, A.M. Cerebral Autoregulation, Brain Injury, and the Transitioning Premature Infant. Front. Pediatr. 2017, 5, 64. [CrossRef] [PubMed]

81. Tsuji, M.; Saul, J.P.; Du Plessis, A.; Eichenwald, E.; Sobh, J.; Crocker, R.; Volpe, J.J. Cerebral Intravascular Oxygenation Correlates With Mean Arterial Pressure in Critically Ill Premature Infants. Pediatrics 2000, 106, 625-632. [CrossRef]

82. Tasker, R.C. Brain vascular and hydrodynamic physiology. Semin. Pediatr. Surg. 2013, 22, 168-173. [CrossRef]

83. Vesoulis, Z.A.; Mintzer, J.P.; Chock, V.Y. Neonatal NIRS monitoring: Recommendations for data capture and review of analytics. J. Perinatol. 2021, 41, 675-688. [CrossRef] [PubMed] 
84. Caicedo, A.; Naulaers, G.; Lemmers, P.; Van Bel, F.; Wolf, M.; Van Huffel, S. Detection of cerebral autoregulation by near-infrared spectroscopy in neonates: Performance analysis of measurement methods. J. Biomed. Opt. 2012, 17, 117003. [CrossRef] [PubMed]

85. Liem, K.D.; Greisen, G. Monitoring of cerebral haemodynamics in newborn infants. Early Hum. Dev. 2010, 86, 155-158. [CrossRef] [PubMed]

86. Delpy, D.T.; Cope, M.; Van Der Zee, P.; Arridge, S.; Wray, S.; Wyatt, J. Estimation of optical pathlength through tissue from di-rect time of flight measurement. Phys. Med. Biol. 1988, 33, 1433-1442. [CrossRef]

87. Villringer, A.; Planck, J.; Hock, C.; Schleinkofer, L.; Dirnagl, U. Near infrared spectroscopy (NIRS): A new tool to study hemo-dynamic changes during activation of brain function in human adults. Neurosci. Lett. 1993, 154, 101-104. [CrossRef]

88. Ferrari, M.; Quaresima, V. A brief review on the history of human functional near-infrared spectroscopy (fNIRS) development and fields of application. NeuroImage 2012, 63, 921-935. [CrossRef]

89. Saager, R.; Berger, A. Measurement of layer-like hemodynamic trends in scalp and cortex: Implications for physiological base-line suppression in functional near-infrared spectroscopy. J. Biomed. Opt. 2008, 13, 034017. [CrossRef]

90. Kirlilna, E.; Yu, N.; Jelzow, A.; Wabnitz, H.; Jacobs, A.M.; Tachtsidis, I. Identifying and quantifying main components of physiological noise in functional near infrared spectroscopy on the prefrontal cortex. Front. Hum. Neurosci. 2013, 7. [CrossRef]

91. Gregg, N.M.; White, B.R.; Zeff, B.W.; Berger, A.J.; Culver, J.P. Brain specificity of diffuse optical imaging: Improvements from superficial signal regression and tomography. Front. Neuroenergetics 2010, 2. [CrossRef]

92. Hakimi, N.; Jodeiri, A.; Mirbagheri, M.; Setarehdan, S.K. Proposing a convolutional neural network for stress assessment by means of derived heart rate from functional near infrared spectroscopy. Comput. Biol. Med. 2020, 121, 103810. [CrossRef]

93. Perdue, K.L.; Westerlund, A.; McCormick, S.A.; Nelson, C.A. Extraction of heart rate from functional near-infrared spectroscopy in infants. J. Biomed. Opt. 2014, 19, 67010. [CrossRef]

94. Holper, L.; Seifritz, E.; Scholkmann, F. Short-term pulse rate variability is better characterized by functional near-infrared spectroscopy than by photoplethysmography. J. Biomed. Opt. 2016, 21, 91308. [CrossRef] [PubMed]

95. Hakimi, N.; Setarehdan, S.K. Stress assessment by means of heart rate derived from functional near-infrared spectroscopy. J. Biomed. Opt. 2018, 23,1-12. [CrossRef] [PubMed]

96. Mirbagheri, M.; Hakimi, N.; Ebrahimzadeh, E.; Setarehdan, S.K. Quality analysis of heart rate derived from functional nearinfrared spectroscopy in stress assessment. Inform. Med. Unlocked 2020, 18, 100286. [CrossRef]

97. Perdue, K.L.; Edwards, L.A.; Tager-Flusberg, H.; Nelson, C.A. Differing Developmental Trajectories in Heart Rate Responses to Speech Stimuli in Infants at High and Low Risk for Autism Spectrum Disorder. J. Autism Dev. Disord. 2017, 47, $2434-2442$. [CrossRef] [PubMed]

98. Lund, C. Medical Adhesives in the NICU. Newborn Infant Nurs. Rev. 2014, 14, 160-165. [CrossRef]

99. Scarpa, F.; Brigadoi, S.; Cutini, S.; Scatturin, P.; Zorzi, M.; DellrAcqua, R.; Sparacino, G. A methodology to improve estimation of stimulus-evoked hemodynamic response from fNIRS measurements. In Proceedings of the 2011 Annual International Conference of the IEEE Engineering in Medicine and Biology Society, Boston, MA, USA, 30 August-3 September 2011; pp. 785-788.

100. Berivanlou, N.H.; Setarehdan, S.K.; Ahmadi Noubari, H. Evoked hemodynamic response estimation using ensemble empirical mode decomposition based adaptive algorithm applied to dual channel functional near infrared spectroscopy (fNIRS). J. Neurosci. Methods 2014, 224, 13-25. [CrossRef] [PubMed]

101. Kamran, M.A.; Jeong, M.Y.; Mannan, M.M.N. Optimal hemodynamic response model for functional near-infrared spectroscopy. Front. Behav. Neurosci. 2015, 9. [CrossRef] [PubMed]

102. Scholkmann, F.; Kleiser, S.; Metz, A.J.; Zimmermann, R.; Pavia, J.M.; Wolf, U.; Wolf, M. A review on continuous wave functional near-infrared spectroscopy and imaging instrumentation and methodology. NeuroImage 2014, 85, 6-27. [CrossRef]

103. Caldwell, M.; Scholkmann, F.; Wolf, U.; Wolf, M.; Elwell, C.; Tachtsidis, I. Modelling confounding effects from extracerebral con-tamination and systemic factors on functional near-infrared spectroscopy. Neuroimage 2016, 143, 91-105. [CrossRef]

104. Orihuela-Espina, F.; Leff, D.R.; James, D.R.C.; Darzi, A.W.; Yang, G.Z. Quality control and assurance in functional near infrared spectroscopy (fNIRS) experimentation. Phys. Med. Biol. 2010, 55, 3701-3724. [CrossRef]

105. Pollonini, L.; Olds, C.; Abaya, H.; Bortfeld, H.; Beauchamp, M.S.; Oghalai, J.S. Auditory cortex activation to natural speech and sim-ulated cochlear implant speech measured with functional near-infrared spectroscopy. Hear. Res. 2014, 309, 84-93. [CrossRef] [PubMed]

106. Pollonini, L.; Bortfeld, H.; Oghalai, J.S. PHOEBE: A method for real time mapping of optodes-scalp coupling in functional near-infrared spectroscopy. Biomed. Opt. Express 2016, 7, 5104-5119. [CrossRef] [PubMed]

107. Sappia, M.S.; Hakimi, N.; Colier, W.N.J.M.; Horschig, J.M. Signal Quality Index: A novel algorithm for quantitative assessment of functional near infrared spectroscopy signal quality. Biomed. Opt. Express 2020, 11, 6732-6754. [CrossRef] [PubMed]

108. Sappia, M.S.; Hakimi, N.; Svinkunaite, L.; Alderliesten, T.; Horschig, J.M.; Colier, W.N. fNIRS signal quality estimation by means of a machine learning algorithm trained on morphological and temporal features. In Biophotonics in Exercise Science, Sports Medicine, Health Monitoring Technologies and Wearables II; SPIE: Bellingham, WA, USA, 2021; p. 11. 